\title{
Resposta humoral, recuperação bacteriana e lesões histológicas em camundongos geneticamente selecionados para bons e maus produtores de anticorpos e $b a l b / c$, frente à infecção por Leptospira interrogans sorovar icterohaemorrhagiae ${ }^{1}$
}

\author{
Márcia Marinho $^{2}$, Helio Langoni ${ }^{3}$, Silvio Luis Oliveira ${ }^{4}$, Rodrigo Carreira ${ }^{3}$, Silvia H.V. \\ Perri $^{5}$ e Maria Cecilia Luvizoto ${ }^{6}$
}

\begin{abstract}
Marinho M., Langoni H., Oliveira S.L., Carreira R., Perri, S.H.V. e Luvizoto M.C. 2002. [Humoral immune response, bacterial recovery and time lesions in mice geneticaly selected for high and low antibody production and in outbreed Balb/c mice face to Leptospira interrogans sorovar icterohaemorrhagiae .] Resposta humoral, recuperação bacteriana e lesões histológicas em camundongos geneticamente selecionados para bons e maus produtores de anticorpos e Balb/c, frente à infecção por Leptospira interrogans sorovar icterohaemorrhagiae. Pesquisa Veterinária Brasileira 23(1):5-12. Laboratório de Microbiologia, Departamento de Apoio, Produção e Saúde Animal FOA, Unesp-Campus de Araçatuba, Cx. Postal 341, Araçatuba, SP 16050-680, Brazil.
\end{abstract}

The aim of the present work was to evaluate the association among the kinetics of humoral immune response, the recovery of viable leptospiras and the intensity of the tissue lesions in mice selected for high $(\mathrm{H})$ and low $(\mathrm{L})$ production of antibodies (selection IV-A) and in mice from the outbreed Balb/c line, inoculated with pathogenic Leptospira interrogans serovar icterohaemorrhagiae. The $\mathrm{H}$ and $\mathrm{L}$ lines showed modifications in some steps of the immune response, mainly in relation to the macrophagic activity, representing extreme phenotypes found in heterogeneous natural populations. Mice were sacrificed in eight moments after the infection. Analysis of the results revealed that from the 7th day after the infection, on line $\mathrm{H}$ mice presented antibodies titles significantly higher as compared to the $\mathrm{L}$ line mice, maintaining the multispecific effect $\mathrm{Balb} / \mathrm{c}$ line mice showed intermediate results between the two lines. Antibodies production worked as a limiting factor to the infection, because when a greater leptospiras recovery was obtained, at the initial phase of the infection, the titles of antibodies were elevated. Inflammatory and degenerative process led to similar lesions in the organs of infected mice. Only a variation in the degree of tissue compromising was observed according to the line. $\mathrm{H}$ line mice showed more extensive lesions than $\mathrm{L}$ and $\mathrm{Balb} / \mathrm{c}$ lines mice. For the Balb/c line mice, the lesions were moderate. As a rule, $\mathrm{H}$ and $\mathrm{Balb} / \mathrm{c}$ mice lines showed a Th2 profile of immune response, with higher indexes of antibody production and gravity of the lesions, while L line mice presented a Th1 profile of immune response.

INDEX TERMS: Leptospirosis, humoral immune response, bacterial recovery, lesions, mice genetically selected, Balb/c.

\footnotetext{
${ }^{1}$ Aceito para publicação em 14 de novembro de 2002.

${ }^{2}$ Laboratório de Microbiologia, Departamento de Apoio, Produção e Saúde Animal FOA, Unesp-Campus de Araçatuba, Cx. Postal 341, Araçatuba, SP 16050-680.

${ }^{2}$ Disciplina de Estatística do Departamento de Apoio, Produção e Saúde Animal FOA, Unesp-Campus de Araçatuba, SP 16050-680.

${ }^{4}$ Núcleo de Pesquisa em Zoonoses NUPEZO-Departamento de Higiene e Saúde Pública, Unesp-Campus de Botucatu, SP 18618-000.

${ }^{5}$ Instituto de Biociências, Unesp-Campus de Botucatu, SP 18618-000.

${ }^{6}$ Disciplina de Patologia, Departamento de Clínica e Cirurgia FOA, UnespCampus de Araçatuba, SP 16050-680.
}

RESUMO.- $O$ presente trabalho teve por finalidade associar a cinética da resposta humoral à recuperação de leptospiras viáveis e à intensidade das lesões teciduais em camundongos geneticamente selecionados para bons (High) e maus (Low) produtores de anticorpos (seleção IV-A), além de camundongos outbreed, Balb/c, inoculados com amostra patogênica de Leptospira interrogans sorovar icterohaemorrhagiae. As linhagens High e Low (seleção IV-A) apresentam modificações em alguns compartimentos da resposta imune, principalmente em relação à atividade macrofágica, representando fenótipos extre- 
mos encontrados em populações naturais heterogêneas. Os camundongos foram sacrificados em oito momentos após a infecção. A análise dos resultados revelou que a partir do $7^{\circ}$ dia após a infecção, os camundongos da linhagem High apresentaram elevação nos títulos de anticorpos estatisticamente significantes quando comparados aos camundongos da linhagem Low, mantendo assim o efeito multiespecífico. Os camundongos $\mathrm{Balb} / \mathrm{c}$ apresentaram resultados intermediários entre as duas linhagens. A produção de anticorpos colaborou como fator limitante à infecção, pois quando obtevese maior recuperação de leptospiras, na fase inicial da infecção, os títulos de anticorpos encontravam-se em elevação. As lesões observadas nos órgãos de camundongos infectados consistiram basicamente nos mesmos processos inflamatórios e degenerativos, que não se alteraram, variando apenas o grau de comprometimento tecidual, de acordo com a linhagem. A linhagem high apresentou lesões mais extensas que as apresentadas pelas linhagens low e Balb/c, sendo que nesta última as lesões foram moderadas. De forma geral a linhagem High e Balb/c apresentaram um perfil de resposta Th2, com o maior índice de produção de anticorpos e gravidade das lesões, enquanto a linhagem Low apresentou um perfil de resposta Th1.

TERMOS DE INDEXAÇÃO: Leptospirose, recuperação bacteriana, lesões, resposta humoral, camundongos geneticamente selecionados.

\section{INTRODUÇÃO}

A leptospirose constitui uma enfermidade bifásica. Tendo início a fase aguda, após a penetração da leptospira pelas membranas mucosas ou pela pele íntegra. Invadem a circulação, multiplicando-se ativamente, para posterior migração em direção a determinados orgãos de eleição, desaparecendo a seguir completamente da circulação, constituindo assim, a fase imune. A imunidade em relação à leptospirose é principalmente, humoral, envolvendo a opsonização de leptospiras por fagócitos como macrófagos e neutróflos (Mitchison et al. 1997). Wang et al. (1984), ressaltam a interação de anticorpos específicos, complemento e macrófagos como responsáveis pelo efeito bactericida sobre amostras patogênicas de Leptospira. Inicialmente, Arean et al. (1963), De Brito et al. (1979) acreditavam que o conjunto de alterações patológicas observadas na leptospirose ocorriam devido à presença de tóxinas circulantes liberadas pela bactéria, ou mesmo pela presença de fatores citotóxicos que estariam presentes no sangue e no plasma de animais com a doença, como demonstraram Kmety et al. (1988). Agindo de maneira aguda, e avançando gradualmente, da luz para a intimidade da célula, o conjunto de lesões observadas na membrana celular e em outras estruturas, em muito se assemelham a processos endotóxicos produzidos por bactérias Gram negativas (Mitchison et al.1997).

Alguns autores atribuem os sinais clínicos da doença aguda a fatores patogênicos, tais como hemolisinas, hialuronidases (Topley et al. 1990), lipases, e injúrias imunopatológicas, e consideram a endotoxemia como um adjuvante no desenvolvimento da patogenia da infecção. Atri- buem também a severidade das lesões ao sorovar envolvido e à sua adaptabilidade ao hospedeiro (Sebastian 1994).

Dobrina et al. (1995) sugerem que o peptideoglicano (PG) presente no arcabouço celular da Leptospira, seria responsável por uma série de efeitos biológicos, in vitro, como ativação do complemento, estimulação da fagocitose por leucócitos e aumento da atividade mitogênica para linfócitos. Ainda correlacionam-no às alterações vasculares generalizadas presentes na leptospirose. Os mesmos autores, utilizando cultura de células do endotélio de capilares umbilicais humanos, infectados com Leptospira interrogans sorovar icterohaemorrhagiae, concluíram que o próprio peptideoglicano da bactéria pode induzir diretamente células do endotélio vascular a aumentar a sua capacidade de adesão para leucócitos polimorfonucleares.

O envolvimento de toxinas na patogênese da leptospirose foi sugerido por (Sheehan 1946, Van Thiel 1948, Miler \& Wilson 1967, Smadel 1985), que observaram lesões no endotélio de capilares do tecido intersticial em rins de hamster, na ausência de leptospiras nestas áreas de injírúria tecidual, sugerindo então a possibilidade da circulação de toxinas. Além disto, há uma certa similaridade entre os achados histológicos e as manifestações clínicas presentes na leptospirose com os observados nas endotoxemias produzidas por bactérias Gram negativas (Arean et al. 1963). Ao longo desses anos, exaustivos trabalhos foram realizados na tentativa de se obter produtos tóxicos liberados por leptospiras. Várias técnicas foram utilizadas, como a do ácido tricloroacético, fenol e etil (Arean et al. 1963), petróleo clorofórmio e fenol (Souza \& Koury 1992), com o objetivo de se conseguir a extração de uma possível toxina patogênica. Entretanto, o que se observa é a presença de vários componentes estruturais presentes na parede celular e que estarião implicados no processo inflamatório; porém, com nenhuma atividade endotóxica (Veronesi 1979). Macrófagos conseguem fagocitar amostras de leptospiras apatogênicas sem a presença de anticorpos específicos. Entretanto, as amostras patogênicas precisam estar opsonizadas para que ocorra a fagocitose por estas células.

Levando-se em consideração a importância dos aspectos imunopatológicos na infecção leptospírica estudou-se a cinética da resposta humoral, a recupersação de leptospiras e o perfil lesional tecidual em camundongos geneticamente selecionados para bons e maus respondedores de anticorpos e outbread Balb/c.

\section{MATERIAL E MÉTODOS}

Como modelo experimental utilizamos às linhagens de camundongos, geneticamente selecionados, inicialmente desenvolvidas por Biozzi et al.(1968), para o estudo da caracterização dos mecanismos reguladores dos fenômenos que participam da resposta imunológica. Este modelo foi obtido pela Seleção genética bidirecional de camundongos bons $(\mathrm{H})$ e maus $(\mathrm{L})$ produtores de anticorpos contra antígenos naturais complexos. A alta ou a baixa capacidade de resposta resulta do efeito aditivo de alelos localizados em vários loci independentes (controle poligênico), que são acumulados progressivamente nos animais $\mathrm{H}$ e L durante o processo seletivo. No 
limite da seleção, estas linhagens, consideradas homozigotas para os alelos relacionados com o caráter selecionador, representam fenótipos extremos encontrados em populações naturais heterogênas. Foram utilizados portanto camundongos machos e fêmeas das linhagens $\mathrm{H}$ e L da Seleção IV-A, e $B A L B / c$, com quatro a oito semanas de idade, provenientes do Biotério do Departamento de Microbiologia e Imunologia, Instituto de Biociências, UnespBotucatu.

Foram constituídos quatro grupos, de cinco animais, dispostos da seguinte maneira:

Grupo 0, Grupo-controle (G0), composto de cinco camundongos pertencentes a cada uma das linhagens, inoculados com $1 \mathrm{~mL}$ de meio de Fletcher, via intraperitoneal. Para cada grupo houve um G0 correspondente.

Grupo 1 (G1), composto de cinco camundongos da linhagem geneticamente selecionada, IV-A, para mau respondedor para anticorpos Low, inoculados com $1 \mathrm{~mL}$ de Leptospira interrogans sorovar icterohaemorrhagiae, via intraperitoneal.

Grupo 2 (G2), composto de cinco camundongos da linhagem geneticamente selecionada, IV-A, para bom respondedor para anticorpos High, inoculados com $1 \mathrm{~mL}$ de de Leptospira interrogans sorovar icterohaemorrhagiae, via intraperitoneal.

Grupo 3 (G3), composto de cinco camundongos $B A L B / c$, inoculados com $1 \mathrm{~mL}$ da amostra patogênica de Leptospira interrogans sorovar icterohaemorrhagiae, via intraperitoneal.

Como inóculo, utilizou-se a cepa icterohaemorrhagiae ( $\left.\mathrm{n}^{\circ} 11437\right)$, do Laboratório de Referência da FIOCRUZ, mantida em meio semisólido de Fletcher, conforme a técnica recomendada pelo Ministério da Saúde (1996). Para restaurar seu poder de virulência foi inoculada em hamsters, $1 \mathrm{~mL}$ via intraperitoneal, e posteriormente recuperada dos rins, utilizando a técnica da Pipeta Pasteur, recomendada pelo Ministério da Saúde (1996). O inóculo foi quantificado, segundo a técnica de Faine (1982), utilizando-se câmara hemocitométrica de Neubauer, estipuladas na dose de $1 \mathrm{~mL}$, contendo $1 \times 10^{6}$ leptospiras/ $\mathrm{mL}$.

A pesquisa de anticorpos anti-Leptospira interrogans sorovar icterohaemorrhagiae foi realizada pela técnica de soroaglutinação microscópica, em lâmina, segundo Martin \& Petit (1918) in WHO (1967). O antígeno para teste foi mantido em meio de EMJH, a $28^{\circ} \mathrm{C}$, utilizando-se apenas as amostras entre o $5^{\circ}$ e $8^{\circ}$ dias de cultivo. $O$ soro dos animais foi obtido por punção do plexo retro-orbital, antes de serem sacrificados e, a seguir, diluído em série de razão dois, a partir do valor inicial 1:50. Considerou-se positivo o soro que na diluição 1:100 aglutinou pelo menos $50 \%$ das leptospiras. O título foi representado pela recíproca da maior diluição em que foram encontradas $50 \%$ das leptopiras aglutinadas.

Os camundongos foram sacrificados, no $2^{\circ}, 4^{\circ}, 7^{\circ}, 10^{\circ}, 14^{\circ}, 21^{\circ}$, $28^{\circ}$ e $35^{\circ}$ dias após a infecção, por deslocamento cervical. Imediatamente procedia-se a lavagem peritoneal, para obtenção de suspensão de células macrofágicas. Neste momento foram retirados o baço para a realização de culturas de células esplênicas. Para o exame histopatológico foram colhidos fragmentos hepáticos, renais, do coração e do pulmão e acondicionados em frascos com formalina tamponada a $10 \%$ em pH de 7,2, para incluísão em parafina, e posterior coloração por Hematoxilina-Eosina (HE) e pela impregnação da prata, técnica de Warthin-Starry para visualização de leptospira (Kerr 1938). Para a recuperação de leptospiras, foram colhidos fragmentos renais e hepáticos.

Para determinar o grau de infecção dos animais, estes foram sacrificados conforme descrito anteriormente fragmentos hepáticos e renais foram colhidos imediatamente após a morte. Macerados, separadamente, na proporção de 1:10 (peso/volume) em solução salina adicionada de neomicina e nitrofurantoína na concentração de $25 \mathrm{ml} / \mathrm{mL}$ de cada droga (Myers 1985). Foram efetuadas diluições seriadas até $10^{-5}$, sendo cultivadas as três últimas diluições em meio de Fletcher a $2,5 \%$, adicionado de $10 \%$ de soro de coelho inativado e estéril, e em meio de caldo Triptose Fosfato (TPB). As culturas foram incubadas à temperatura de $30^{\circ} \mathrm{C}$ durante o período de 60 dias, observando-se semanalmente o crescimento bacteriano, revelado por anel de opalescência no meio de Fletcher, conhecido como anel ou zona de Dinger. Em caso positivo, pipetou-se $1 \mathrm{~mL}$ do mênstruo obtido no meio de TPB, verificando-se em câmara hemocitométrica de Neubauer, a presença e a quantidade de leptospiras.

Para a comparação dos títulos sorológicos obtidos pelos camundongos $\mathrm{Balb} / \mathrm{c}$ e geneticamente selecionados (bons e maus produtores de anticorpos seleção IV-A), quando inoculados com amostra patogênica de $L$. interrogans sorovar icterohaemorrhagiae, utilizou-se a prova não paramétrica de Kruskal -Wallis, para amostras independentes Zar (1996).

\section{RESULTADOS}

Inicialmente foi feita uma triagem, utilizando-se 24 antígenos de leptospiras, sendo utilizados os seguintes sorovares: icterohaemorrhagiae, pomona, tarassovi, copenhageni, hardjo, bratislava, autumnalis, pyrogenes, canicola, wolffi, grippotyphosa, andamana, djasiman, hebdomadis, serjoe, shermani, brasiliensis, cynopteri, whitcombi, hebdomadis, javanica, patoc, castellonis e butembo. A adoção desta medida teve por finalidade impedir que animais previamente infectados ou portadores integrassem os grupos experimentais. Os títulos de anticorpos produzidos pelos camundongos após inoculação com a amostra de Leptospira interrogans sorovar icterohaemorrhagiae foram expressos em logarítimo na base 10 (Fig. 1).

A análise destes resultados revela que não há diferença significativa entre as linhagens geneticamente selecionadas Low, High, e camundongos consangüíneos $B A L B / c$ nos $2^{\circ}$ e $4^{\circ}$ dias após a inoculação. Entretanto, do $7^{\circ}$ ao $35^{\circ}$ dia, a linhagem $\mathrm{H}$ apresentou títulos de anticorpos significativamente

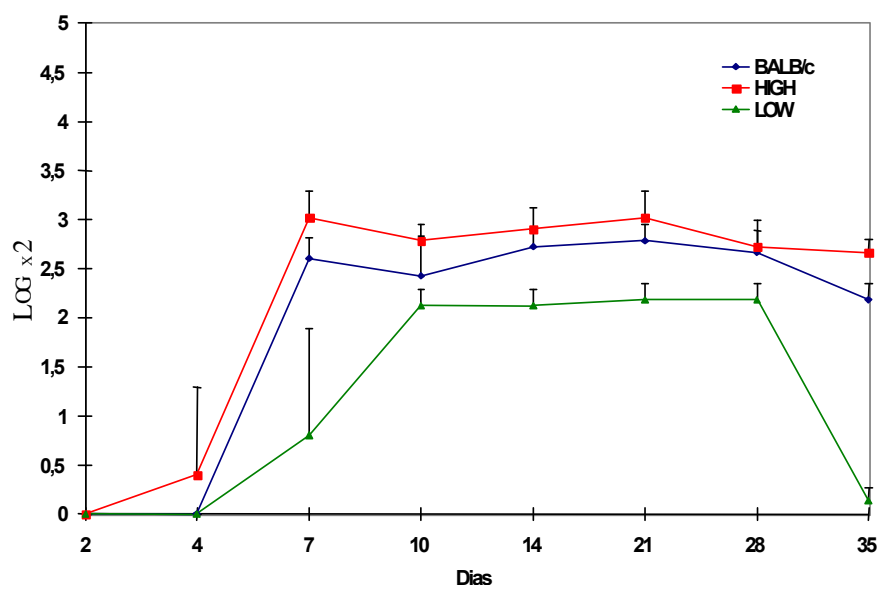

Fig. 1. Avaliação da produção dos títulos sorológicos, frente ao antígeno de Leptospira interrogans sorovar icterohaemorrhagiae, dos camundondos Low, High e BALB/c, inoculados com $1 \times 10^{6}$ leptospiras/mL. Os momentos em que houve diferença entre as linhagens $\mathrm{H}$ e $\mathrm{L}$ foi representada pelo símbolo de adição. Resultados expressos em logaritmo do título sorológico. Prova nãoparamétrica de Kruskal-Wallis para amostras independentes $(\alpha=0,05)$. 
Quadro 1. Recuperação de leptospiras, a partir de órgãos de camundongos consangǘneos $B A L B / c$, e de linhagens selecionadas Low e High, submetidas à inoculação de $1 \times 10^{6}$ Leptospira interrogans sorovar icterohaemorrhagiae. Resultados expressos em porcentagem

\begin{tabular}{|c|c|c|c|c|c|c|}
\hline \multirow[t]{3}{*}{ Dias } & \multicolumn{6}{|c|}{ Animais } \\
\hline & \multicolumn{2}{|c|}{$\mathrm{BALB} / \mathrm{c}$} & \multicolumn{2}{|c|}{ Low } & \multicolumn{2}{|c|}{ High } \\
\hline & $\begin{array}{c}\text { Fígado }^{\mathrm{a}} \\
48^{\mathrm{A}} \\
( \pm 17,88)\end{array}$ & $\begin{array}{c}\operatorname{Rima}^{\mathrm{b}} \\
48^{\mathrm{AB}} \\
( \pm 33,46)\end{array}$ & $\begin{array}{c}\text { Fígado }^{\mathrm{a}} \\
24^{\mathrm{A}} \\
( \pm 17,88)\end{array}$ & $\begin{array}{c}\operatorname{Rim}^{\mathrm{a}} \\
73,33^{\mathrm{A}} \\
( \pm 11,54)\end{array}$ & $\begin{array}{c}\text { Fígado }^{\mathrm{a}} \\
24^{\mathrm{A}} \\
( \pm 8,94)\end{array}$ & $\begin{array}{c}\operatorname{Rim}^{\mathrm{b}} \\
28^{\mathrm{B}} \\
( \pm 10,95)\end{array}$ \\
\hline 2 & $60^{A}$ & $40^{\mathrm{A}}$ & $60^{A}$ & $60^{A}$ & - & $20^{A}$ \\
\hline 4 & $60^{A}$ & $60^{\mathrm{A}}$ & $20^{A}$ & $80^{A}$ & $40^{\mathrm{A}}$ & $40^{A}$ \\
\hline 7 & $60^{A}$ & $100^{A}$ & $20^{A}$ & - & $20^{A}$ & $40^{A}$ \\
\hline 10 & -** & $20^{A}$ & $20^{A}$ & $80^{A}$ & $20^{A}$ & $20^{A}$ \\
\hline 14 & $20^{A}$ & - & $40^{\mathrm{A}}$ & - & - & - \\
\hline 21 & . & - & - & - & $20^{A}$ & - \\
\hline 28 & $40^{A}$ & - & - & - & - & - \\
\hline 35 & - & $20^{A}$ & - & - & $20^{A}$ & $20^{A}$ \\
\hline
\end{tabular}

*O traço representa a não recuperação do microrganismo a partir de fragmentos dos órgãos em meio de cultura.

superiores a linhagem $\mathrm{L}$, mantendo assim o efeito multiespecífico normalmente observado nesta seleção. A linhagem $B A L B / c$ apresentou resposta semelhante à linhagem $\mathrm{H}$, com diferenças significativas de produção de anticorpos em relação à linhagem $\mathrm{L}$ no $7^{\circ}, 14^{\circ}, 21^{\circ}, 28^{\circ}$ e $35^{\circ}$ dias.

Os resultados expressos no Quadro 1 mostram que a recuperação bacteriana no fígado e rins ocorreu a partir do $2^{\circ}$ dia pós-inoculação, em todas as linhagens inoculadas, com pico máximo nos $4^{\circ}$ e $7^{\circ}$ dias. Após o $14^{\circ}$ dia, observou-se que a recuperação foi irregular e decrescente.

Para cada grupo de cinco animais, as médias da recuperação de bactérias viáveis a partir dos órgãos de camundongos, seguidas de letras maiúsculas iguais não diferem significativamente $(p>0,05)$ pela Análise de Variância

Para cada grupo de cinco animais, médias seguidas de letras minúsculas iguais não diferem significativamente $(p>0,05)$ pela Análise de Variância Teste $T$ de StudentNewman-Keuls.

As letras minúsculas iguais não diferem significativamente $(p>0,05)$ e não demonstram que há diferença estatística entre as linhagens $p<0,05$. As médias encontram-se seguidas por letras maiúsculas e os desvio-padrão estão representados entre parênteses. Os resultados foram submetidos à Análise de Variância com médias repetidas e Teste de comparações múltiplas de Student-Newman-Keuls.

Ao exame hispatológico dos orgãos dos camundongos HIV-A, a partir do $2^{\circ}$ dia da inoculação não foram verificadas alterações microscópicas no parênquima renal. Entretanto, nos dias posteriores, verificou-se degeneração hidrópica tubular e alterações nucleares indicativas de necrose, que se acentuaram-se a partir do $7^{\circ}$ dia, com necrose tubular, principalmente próximo à região córtico-medular. No interstício havia infiltrado mononuclear e congestão vascular. A partir do $14^{\circ}$ dias observou-se degeneração hidrópica com presença de Leptospira spp em cortes histológicos corados pela Técnica de Wartin-Starrey. O processo inflamatório persistiu até o $28^{\circ}$ dia, com predomínio de infiltrado mononuclear focal, principalmente, nas regiões perivasculares. Havia acentuada celularidade glomerular. No $35^{\circ}$ dia, verificou-se áreas de infiltrado focal glomerular, com espessamento de membrana basal glomerular. Todo o parênquima renal apresentava infiltrado intersticial linfoplasmocitário intenso associado a áreas de degeneração da porção tubular cortical. No exame do fígado revificou-se discreto infiltrado focal, que acentuouse após o $4^{\circ} \mathrm{dia}$, exibindo células polimorfonucle-ares e mononucleares, com início de necrose e acidofilia do citoplasma dos hepatócitos circunjacentes ao foco inflamatório. A partir do $10^{\circ}$ pós-inoculação (p.i.), os hepatócitos exibiram intensa vacuolização caracterizando degeneração vacuolar, além de alterações nucleares, como cariorrexia, cariólise e picnose, com a presença de células mononucleares nos espaços porta. Estas células inflamatórias permaneceram até $\mathrm{o} 21^{\circ}$ dia. Havia também, discretas áreas de necrose focal com intensa degeneração hidrópica vacuolar de hepatócitos.

No pulmão observou-se a presença de infiltrado focal com células polimorfonucleares e mononucleares junto à pleura visceral. No miocárdio, a presença de áreas isoladas de degeneração hialina de Zenker e de cariorrexia, deu-se principalmente nas regiões do ápice e da base do músculo papilar do ventrículo direito.

A análise microscópica dos orgãos de camundongos LIVA, como do fígado, revelou no $2^{\circ}$ dia p.i., áreas de congestão hepática, com discretos hepatócitos em megalocitose, com um ou dois núcleos, sendo ocasional o aparecimento de inclusões. Figuras de mitose do tipo interfase, também estavam presentes. As células de Kupffer apresentavam-se com um aspecto reativo com núcleo e citoplasma aumentados de volume. Áreas de infiltrado focal, com predomínio de células mononucleares, foram encontradas difusamente sob o parênquima hepático, na região periportal. Próximo aos ductos biliares foram observados infiltrados celulares, caracterizando portanto, o processo de pericolangite e colangite, sendo evidenciado até o $14^{\circ}$ dia após a infecção. O quadro inflamatório supracitado, estendeu-se pelo $4^{\circ}, 7^{\circ}, 10^{\circ}, 14^{\circ} \mathrm{e}$ $21^{\circ}$ dias após a infecção. Com o acentuado agravamento dos processos inflamatório, e degenerativo. Foi evidente, o predomínio de células polimorfonucleares e áreas de necrose junto aos infiltrados, os quais, com o desenvolver da infecção, localizavam-se na região periacinar. A partir do $21^{\circ}$ dia da infecção, observou-se uma regressão do processo inflamatório. $O$ parênquima hepático apresentou discretas áreas de infiltrado focal, com predomínio de células mononucleares, no entanto, houve ainda evidência de áreas de necrose celular.

Na histologia renal notou-se áreas de intenso processo degenerativo, a partir do $2^{\circ}$ dia da infecção, estendendo-se durante todo o período experimental, variando apenas na severidade e grau da lesão, que se intensificava com a evolução do processo. Observou-se áreas de degeneração hidrópica com vacuolização e células picnóticas. Os glomérulos apresentavam moderada hipercelularidade, em função de células axiais, exibindo áreas de necrose, principalmente nos túbulos distais. Os túbulos tinham um aspecto dilatado e eram revestidos por células epiteliais com citoplasma basofílico. A se- 
veridade destas lesões também variaram em função do aumento do tempo de exposição ao microrganismo. A nefrite intersticial, no momento da infecção, apresentou acúmulos de células mononucleares, suplantados a partir do $4^{\circ}$ dia, por células polimorfonucleares. Áreas de intenso edema, vasodilatação com congestão e tumefação endotelial acompanharam o processo inflamatório em todos os momentos do experimento. Do $4^{\circ}$ ao $10^{\circ}$ dia, além das lesões supracitadas, observou-se em determinados focos, a presença de aderência da cápsula de Bowman. A necrose tubular foi evidente a partir do $4^{\circ}$ dia, atingindo grau acentuado no $10^{\circ}$ e no $14^{\circ}$ dia, mantendo-se até o $35^{\circ}$ dia de observação. No pulmão, observou-se a presença de infiltrado inflamatório focal e perivascular ao $14^{\circ}$ dia. No coração, nos septos interventriculares, foram observadas áreas de degeneração, com ausência de estriações do músculo cardíaco e com intensa área de acidofilia celular (degeneração hialina), que no $14^{\circ}$ dia foi acompanhada de áreas de necrose, com intensa proliferação de fibroblastos.

Os exames histológicos de fragmentos hepáticos de animais da linhagem $B A L B / c$ revelaram em todos os momentos do experimento discretíssima presença de infiltrado celular, com predomínio de células polimorfonucleares, que posteriormente foram suplantadas por células mononucleares de acordo com a evolução da infecção. A partir do $2^{\circ}$ dia, verificou-se a presença de infiltrado localizado junto ao espaço porta, que foi tornando-se difuso até o $35^{\circ}$ dia de observação. As células de Kupffer encontravam-se ligeiramente hiperplásicas e com hipereatividade ao longo do experimento. Ao $28^{\circ}$ dia, detectou-se megalocitose, megacariólise com necrose celular, porém, de ocorrência rara e em pontos isolados do ácino hepático. À histologia do rim, foi observada acentuada degeneração hidrópica, com necrose tubular em determinados pontos do parênquima. Ressalta-se também a presença de hipercelularidade nos tufos glomerulares, também evidenciados em todos os momentos da infecção. Ao $14^{\circ}$ dia, observou-se aderência da cápsula de Bowman. A partir do $2^{\circ}$ dia de infecção, verificou-se a presença de discretíssimas áreas de degeneração hialina, tornando-se mais intensas após o $10^{\circ}$ dia. No pulmão, já no $2^{\circ}$ dia de observação, verificou-se áreas de congestão vascular, com infiltrado intersticial de células mononucleares, que foram suplantadas por polimorfonucleares. A partir do $7^{\circ}$ dia, o acúmulo de células inflamatórias foram visualizados de forma mais difusa, localizando-se próximo a região do hilo, sendo formado predominantemente por células mononucleares, estendendo-se, até o $28^{\circ}$ dia, por todo o parênquima até a região da pleura. Todas as lesões, entretanto, variaram de discretas a moderadas, quando comparadas com os animais das linhagens anteriores.

\section{DISCUSSÃO E CONCLUSÃO}

Na leptospirose experimental, o modelo murino não é rotineiramente utilizado, uma vez que camundongos normais geralmente apresentam resistência à infecção. As linhagens de camundongos $\mathrm{L}_{\mathrm{IV}-\mathrm{A}}$ e $\mathrm{H}_{\mathrm{IV}-\mathrm{A}}$ apresentam modificações na pro- dução de anticorpos e atividade metabólica de macrófagos, demonstrando graus variados de resistência e sensibilidade à infecções por parasitas de multiplicação extracelular e/ou intracelular.

Considerando-se as características genéticas dos camundongos $\mathrm{L} \mathrm{e} \mathrm{H}$ selecionados, simultaneamente às modificações fenotípicas na expressão dos mecanismos básicos de resistência, e suas respectivas atribuições na defesa contra vários tipos de infecções, é possível prever o comportamento dessas linhagens mediante alguns modelos clássicos de infecção, cujo mecanismo protetor já esteja bem esclarecido, assim como a sua elucidação nos casos ainda não estabelecidos.

Além disso, as diferenças de interlinhagens na imunidade anti-infecciosa podem ser observadas na resistência inata ou induzida por vacinação. Quando a infecção é menos grave, e $o$ animal sobrevive por tempo suficiente para eliciar uma resposta imune, essa diferença geralmente ocorre nos dois tipos de resistência (Masuzawa et al. 1990). Os camundongos $B A L B / c$ foram utilizados, por tratar-se de uma linhagem consangüínea, de distribuição internacional, e por apresentar padrão intermediário de resposta imune em relação às linhagens $\mathrm{H}$ e $\mathrm{L}$.

A recuperação de Leptospira interrogans sorovar icterohaemorrhagiae, a partir de fragmentos de fígado e rins, de camundongos $\mathrm{L}_{\mathrm{IV}-\mathrm{A}}, \mathrm{H}_{\mathrm{IV}-\mathrm{A}}$, e $B A L B / c$, ocorreu de forma praticamente constante até $\mathrm{o} 10^{\circ}$ dia após a infecção, nos três grupos de animais. Posteriormente, esta ocorreu de forma intermitente nos camundongos $\mathrm{H}_{\mathrm{IV}-\mathrm{A}}$, e $B A L B / c$, uma vez que, a partir do $14^{\circ}$ dia, da inoculação observou-se o clearence total em camundongos $\mathrm{L}_{\mathrm{IV}-\mathrm{A}}$, o que pode ser explicado pela maior atividade metabólica dos macrófagos dos camundongos $\mathrm{L}_{\mathrm{IV}-\mathrm{A}} \mathrm{em}$ relação aos $\mathrm{H}_{\mathrm{IV}-\mathrm{A}}$. Os fragmentos provenientes dos rins demonstraram que houve diferença entre os camundongos $\mathrm{L}_{\mathrm{IV}-\mathrm{A}}$ e $\mathrm{H}_{\mathrm{IV}-\mathrm{A}}$, mas a análise estatística dos resultados obtidos, a partir dos fragmentos de fígado, revelou que não houve diferença entre os três grupos, e que também não diferiram entre eles ao longo do experimento. Embora, os resultados obtidos como camundongos $B A L B / c$ não sejam estatisticamente diferentes em relação aos das linhagens $\mathrm{L}_{\mathrm{IV}-\mathrm{A}}$, os mesmos apresentaram um comportamento semelhante aos observados pelos camundongos $\mathrm{H}_{\mathrm{IV}-\mathrm{A}}$, com relação à recuperação leptospírica.

Gheorghiu et al. (1985) estudaram a resistência do Mycobacterium bovis (BCG) em camundongos L e $\mathrm{H}$ da Seleção I, utilizando a taxa de multiplicação da bactéria no baço. Observou-se que esse efeito ocorre de forma mais rápida na linhagem $\mathrm{H}$ do que na $\mathrm{L}$; nas duas primeiras semanas pósinoculação intravenosa. A partir deste momento, a contagem de unidades formadoras de colônias nos orgãos analisados decresce rapidamente, e 12 semanas após a inoculação, foi encontrado um número maior de bactérias viáveis nos maus respondedores. Esta cinética sugere que na fase inicial, a multiplicação do BCG foi muita mais rápida na linhagem $\mathrm{H}$, em função de um defeito inato do macrófago, que resulta, consequentemente, na maior indução imunitária nesta linhagem do que na $\mathrm{L}$. 
Os roedores funcionam como portadores permanentes para Leptospira na natureza, mantendo a bactéria inviolada no interior dos túbulos renais por longos períodos. No presente estudo, o clearence da leptospira ocorreu de forma diferente nas linhagens estudadas. Este fato pode estar associado à maior resistência dos camundongos Low à infecção.

A produção de anticorpos pelos camundongos $\mathrm{L}_{\mathrm{IV}-\mathrm{A}}, \mathrm{H}_{\mathrm{IV}-\mathrm{A}}$ e $B A L B / c$, revelam uma maior resposta dos camundongos $\mathrm{H}_{\mathrm{IV} \text { - }}$ A em comparação à $\mathrm{L}_{\mathrm{IV}-\mathrm{A}}$, mantendo, portanto, o efeito multiespecífico destas linhagens. Comparando os títulos de anticorpos dos $B A L B / c$ com os $\mathrm{H}_{\mathrm{IV}-\mathrm{A}}$, não se observou diferenças significativas entre si, permanecendo os camundongos $B A L B / c$ como um grupo intermediário entre as linhagens $L$ e H. A comparação dos resultados com relação à recuperação de leptospiras e com a produção de anticorpos, mostrou uma correlação positiva entre eles, demonstra por maior recuperação de leptospiras no início da infecção, enquanto os títulos de anticorpos apresentavam-se baixos. Quando ocorreu um aumento da produção de anticorpos, observou-se queda da recuperação de leptospiras, caracterizando, portanto, que o nível de anticorpos pelo menos em parte foi fator limitante à infecção, pois o isolamento do patógeno a partir dos túbulos renais de roedores, durante a fase imune, ocorre por um longo período.

O maior número de células formadoras de anticorpos no baço de camundongos $\mathrm{H}$, não está relacionado com a capacidade de produção de anticorpos em resposta a mitógenos de células B, como lipopolissacarídeo de $E$. coli e a tuberculina, in vitro, quando comparados ao de camundongos L ( Biozzi et al.1972, Ferreira et al. 1975, Reis et al. 1989).

Mouton et al. (1985) pesquisando a resistência inata à Klebsiella pneumoniae, não observaram diferenças entre as linhagens HI e LI quando quantidades crescentes desta bactéria, inativadas pelo calor, foram administradas a esses animais, dez dias previamente à inoculação intravenosa letal. Os resultados mostraram que a dose de vacinação requerida para a proteção seria 1000 vezes menor nos camundongos HI. O nível de anticorpo produzido também foi um fator limitante para a resistência, pois a transferência passiva de soro imune induziu proteção completa.

Com relação ao efeito protetor de anticorpos produzidos para essas infecções, por microrganismos extracelulares, utilizando-se como modelos experimentais os animais das linhagens L e H, Seleção I, tem-se confirmado a maior resistência de camundongos $\mathrm{H}$, como a desencadeada por Trypanosoma cruzi ( Heuman et al. 1979), vírus da raiva (Kierzembaum et al. 1976) e Plasmodium bergei (Nilsson et al. 1979). O exame histológico dos fragmentos dos orgãos revelaram alterações morfológicas semelhantes entre as três linhagens, variando, entretanto, o grau de severidade das lesões durante os períodos analisados. As lesões foram evidentes após o $2^{\circ}$ dia da inoculação, progredindo, ao longo da infecção, tornando-se mais intensas ao $10^{\circ}$ e $14^{\circ}$ dia, estacionando posteriormente. As alterações histológicas do parênquima hepático, variaram desde a ocorrência de infiltrado com células inflamatórias até áreas de degeneração hepática, com necrose de hepatócitos. No parênquima renal, as alterações predominantes foram relacionadas à degeneração hidrópica acidofílica, com aderência da cápsula de Bowman, pericolangite e necrose tubular. Ressaltam-se ainda, as lesões de miocárdio com degeneração hialina de Zenker e o infiltrado de células inflamatórias no pulmão. Uma vez que, as lesões não foram quantificadas, não se pode afirmar que houve diferença significativa, apesar destas revelarem um maior comprometimento do parênquima dos orgãos dos animais $\mathrm{H}$, quando comparadas às lesões dos camundongos $\mathrm{L}$ e $B A L B / c$; sendo que, neste último, as lesões apresentaram grau moderado.

As lesões presentes na patogenia da leptospirose, nem sempre são causadas pela agressão tecidual direta do agente, uma vez que nem sempre o mesmo se encontra na área lesada. Na glomerulonefrite do cão, a injúria tecidual relaciona-se à reação inflamatória por depósitos de imuno complexos presentes nos capilares do glomérulo (Taylor et al. 1970). A uveíte equina resulta da resposta inflamatória, a partir da reação cruzada entre antígenos leptospíricos e proteínas teciduais presentes na córnea e cristalino de eqüinos. Observa-se em ovinos com leptospirose, um mecanismo patogênico distinto de hemólise direta causada por hemolisina leptospírica, em que a IgM atua como uma hemaglutinina crioreagente, podendo desencadear uma crise hemolítica, no momento em que os animais são expostos à baixa temperatura ( Sebastian 1994).

A despeito dos resultados obtidos, deve-se inferir sobre a provável produção de metabólitos liberados frente à infecção por Leptospira interrogans sorovar icterohaemorrhagiae, uma vez que as lesões iniciaram, predominantemente, ao redor de vasos sanguíneos, difundindo-se posteriormente para o resto do parênquima, sugerindo a circulação de alguma toxina ou fator tóxico (Higuchi 1930, Dobrina et al. 1957, Iamamura et al. 1957, Fukushima et al. 1992).

Ao se comparar os resultados histológicos com os da literatura, observa-se que no presente estudo variou o grau de intensidade das lesões renais, hepáticas, cardíacas e pulmonares de acordo com a linhagem. As lesões foram mais acentuadas nos camundongos High, quando comparadas as dos camundongos das linhagens Low e BALB/c. Silva et al. (1995) abordaram aspectos hematológicos, histológicos e imunohistoquímicos na síndrome hemorrágica presente na leptos-pirose experimental em cobaias inoculadas com amostra virulenta de Leptospira interrogans copenhageni, e sugeriram possíveis mecanismos patogênicos responsáveis pelo quadro além de enfatizarem que a agressão tóxico-anóxica do endotélio vascular seria provocada pela ação direta da bactéria; e que produtos do seu metabolismo estariam diretamente relacionados à coagulação intravascular disseminada (CIVD). De Brito et al. (1992), demonstraram por imunoeletromicroscopia, a afinidade de antígenos leptospíricos para a membrana celular do hospedeiro, sugerindo uma provável interação com proteínas da superfície celular, que antecederia à invasão bacteriana. Em soros de pacientes com leptospirose têm se encontrado altos níveis de fator de necrose tumoral (Estover et. al. 1991, Friedland \& Warrel 1991), e devido à sua franca atividade inflamatória 
associam a sua presença à patogênese da infecção (Cinco et al. 1996).

Na leptospirose a produção de anticorpos é importante na defesa do hospedeiro. Entretanto, como verificou-se nesta pesquisa este fato não parece ser o mais importante, pois a produção de anticorpos da linhagem HIV-A foi mais elevada, com lesões mais severas e com uma maior recuperação de bactérias, em relação à linhagem LIV-A. Acredita-se que se deva à interação de anticorpos com macrófagos pelo fenômeno de opsonização, associado ao fato da linhagem $L$ apresentar maior atividade metabólica de macrófagos que a $\mathrm{H}$.

Merien et al. (1997), utilizando primocultivo de Leptospira interrogans sorovar icterohaemorrhagiae em células Vero, demonstraram que a sua capacidade invasiva foi significativamente suprimida, quando foram tratadas com monodansylcadaverine, sugerindo que a interiorização da bactéria esta associada a um processo de endocitose mediada por receptor. Sugerem ainda, que, na patogênese da infecção, haja apoptose de macrófagos por um mecanismo pouco esclarecido, e que tais fatores de virulência estão diretamente relacionados a habilidade de sobrevivência do patógeno no interior do hospedeiro.

As linhagens $\mathrm{H}_{\mathrm{IV}-\mathrm{A}}$ e $B A L B / c$ apresentaram perfil Th2 de resposta, com maior produção de anticorpos, de IL-4 e maior gravidade das lesões; enquanto que a linhagem $\mathrm{L}_{\mathrm{IV}-\mathrm{A}}$ apresentou um perfil Th 1 com maior produção de INF-g, atividade macrofágica e menor comprometimento de lesões teciduais. Outros experimentos devem ser conduzidos para elucidar estes resultados, principalmente com estudos de imunohistoquímica, com o objetivo de se detectar citocinas e o envolvimento destas nas lesões.

Os resultados indicam que populações naturais heterogêneas, representadas pelas linhagens de camundongos $\mathrm{H}_{\mathrm{IV}-\mathrm{A}} \mathrm{e}$ $\mathrm{L}_{\mathrm{IV}-\mathrm{A}}$ podem apresentar comportamentos distintos em relação à infecção leptospírica. Não somente a resposta humoral, é importante para a contenção do processo infeccioso, mas também a resposta imune celular, pela produção de citocinas e atividade macrofágica.

Agradecimentos.- À Fundação de Amparo a Pesquisa do Estado de São Paulo (FAPESP proc. $n^{\circ}$ 0437-5) pelo financiamento do projeto.

\section{REFERÊNCIAS}

Arean V.M., James H. \& Green M.S. 1963. The Pathogenesis of leptospirosis: toxin production by icterohaemorrhagiae. Am. J. Vet. Res. 25:836-843.

Biozzi G., Stittei C., Mouto, D., Bouthillier Y. \& Descreusefond C. I. 1968. Sélection articielle pour la production d'anticorps chez la souris. Ann. Inst. Pasteur 115:960-965.

Biozzi G., Stittei C., Mouton, Bouthillier, Y. \& Descreusefond C. 1972. Cytinamics of the immune response in two lines of mice genetically selected for high and low antibody synthesis. J. Exp. Med. 135:1071.

Cinco M., Vecile E., Murgia R., Dobrina P. \& Dobrina A. 1996. Leptospira interrogans and Leptospira peptidoglycans induce the release of tumor factor alpha from human moncytes. FEMS (Fed. Europ. Microbiol. Soc.) Microbiol. Lett. 138, p. 211.

De Brito T. \& Böhm G.M. 1979. Yasuda, P.H. Vascular damage in acute experimental leptospirosis of Guinea-pig. J. Pathol. 128: 177-182.

Dobrina A., Nardon E., Vecicle E., Cinco M. \& Patriarca P. 1995. Leptospira icterohaemorrhagiae and Leptospira peptideoglicans induce endothelial cell adhesiveness for polymorphonuclear leukocytes. Infect. Immun. 63:29952999.

Estavoger J.M., Racadot E., Covetdic G., Leroy J. \& Grosperrin L. 1991. Tumor necrosis factor in patients with Leptospirosis Rer. Infect. Dis. 13:12451246.

Faine S. 1982. Guidelines for the control of leptospirosis. WHO, Geneva, p. 83. Ferreira V.C.A., Gennari M., Reis M.H., Siqueira M., Stiffel C., Mouton D. \& Biozzi, G. 1985. Pontentialities of immunocompetent cells in high and low antibody producing lines of mice obtained by selective breedings for responsiveness to flagellar or somatic antigens of salmonella J. Immunogenetics. 12:309-319.

Friedland J.S. \& Warrel D.A. 1991. The arish-Herxheimer reaction in Leptospirosis: possible pathogenesis and review. Vet. Infect. Dis. 13:207-210.

Fukushima B., Hosoya S. \& Ma. 1926. Study of culture media for spirochaeta. Sci. Rep. Gov. Inst. Infect. Dis. 5:151-169.

Gheorghiu M., Mouton D., Lecoeur H., Lagranderie M., Mevel J.C. \& Biozzi G. 1985. Resistance of high and low antibody responder lines of mice to the growth of avirulent (BCG) and virulent (H37Rv) strains od mycobacteria. Clin. Exp. Immunol. 59:177-184.

Heuman A.M., Stiffel C., Monjour L., Bucci A. \& Biozzi G. 1979. Correlation between genetic regulation of antibody responsiveness and protective immunity induced by Plasmodium bergei vaccination. Infect. Immun. 24:829836.

Higuchi S. 1930. Untersuchungen über das Toxin der Spirochaeta (Leptospira). Fukuota Acta Medica 24:3-5.

Iamamura S., Kuribayashi K. \& Kameta M. 1957. Studies on toxins of Pathogenic Leptospirae. Jpn. J. Microbiol. 1:43-47.

Kerr D.A. 1938. Improved Warthin-Starry method as staining spirochetes in tissue section. An. J. Clin. Pathol. 2:63-67.

Kierzembaum F. \& Howard J.G. 1976. Mechanisms of resistence aganist experimental $T$. cruzi infections: the importance of antibodies and antibodyforming capacity in the Biozzi; high and low responder mice. J. Immunol. 116:1208-1211.

Masuzawa T., Nakamura R., Suzuki R. \& Yanagihara Y. 1990. Immunochemical properties of protective Ag (Pág) of Leptopira interrogans sorovar lai, p. 315-331. In: Leptospirosis Research Conference. University of Tokyo Press, Tokyo.

Merien F., Baraton G. \& Perolat P. 1997. Invasion of Vero cells and induction of apoptosis in macrophages by pathogenic Leptospira interrogans are correlated with virulence. Infect. Immun. 65:729-738.

Miller N.G. \& Wilson R.B. 1967. Electron microscopic study of relationship of Leptospira pomona to the renal tubules of hamsters during acute and chronic leptospirosis. Am. J. Med. 1:75-91.

Ministério da Saúde 1996. Manual de Controle Leptospirose. Divisão Nacional de Zoonose, Secretaria Nacional de Ações Básicas de Saúde, Ministério da Saúde. Série A: Normas e Manuais Técnicos 48, Centro de Documentação do Ministério da Saúde, Brasília, p. 71.

Mitchison M., Bulach D.M., Vinh T., Rajakurmar K., Faine S. \& Adler B. 1997. Identification and characterizacion of dTDP-rhaminose biosynthesis and transfer genes of lipopolysaccaride related rfb locus in Leptospira interrogans sorovar copenhagini. J. Bacteriol. 179:1262-1271.

Mouton D., Stiffel C. \& Biozzi G. 1985. Genetic factors of immunity aganist infection. Annu. Immunol. Lett. 136:131-141.

Myers D.M. 1985. Manual de métodos para el diagnóstico de laboratório de la leptospirosis. Nota técnica, p. 30, Centro Pan Americano de Zoonosis/ OPS/OMS, Buenos Aires.

Kmety E. \& Dikken H. 1988. Joint Meeting of European Leptospira Workers, 6, Brno, Czechoslovakia. Proc. 6th Joint Meeting of European Leptospira Workes, Brno, Czechoslovakia, p. 6.

Nilsson M.R., Santa'anna O.A., Siqueira M., Nilsson T.T. \& Genari M. 1979. Rabies virus immunity in genetically selected high and low-responder lines of mice. Infect. Immun. 2:23-26. 
Reis M.H., Piatti R.M., Ibáñez O.M., Cabrera W.H. \& Siqueira M. 1989. Atividade de linfócitos $\mathrm{T}$ auxiliaries em linhagens de camundongos bons e maus produtores de anticorpos: efeito do tratamento com anticorpo monoclonal anti-L3T4. IV Reunião Anual da Federação de Sociedades de Biologia Experimental. Anais $14^{\circ}$ Congr. Bras. Imunologia, Caxambu, p. 402.

Sebastian E. 1994. Leptospirosis. J. Am. Vet. Med. Assoc. 205:1518-1523.

Silva J.J.L., Souza Neto B.A., Lilembaum W., Alvin M.E.AM. \& Oliveira A.V. 1995. The hemorragic syndrome of leptospirosis: an experimental study in Guinea pigs. Revta Soc. Bras. Med. Trop. 28: 169-177.

Souza L. \& Koury Mc. 1992. Chemical and biological properties of endotoxin from Leptospira interrogans serovares canicola and icterohaemorrhagiae. Braz. J. Med. Biol. Res. 25:467-475.

Taylor P.L., Hanson L.E. \& Simon J. 1970. Serologic, pathologic and immunologic features of experimentally induced leptospiral nephritis in dog. Am. J. Vet. Res. 31:1033-1049.

Topley W.W.C., Wilson's G.S. \& Miles A.A. 1990. Principles of Bacteriology, Virology and Immunity. 8th ed. London, p. 604.

Veronesi R. 1991. Doenças Infecciosas e Parasitárias. $8^{\mathrm{a}}$ ed. Koogan Guanabara, Rio de Janeiro, p.579.

Wang B., Sullivan J.A. \& Sullivan G.W. 1984. Role of specific antibody in interaction of leptospiras with human monocytes and monocyte-derived macrophages. Infect. Immun. 46:809-813.

World Health Organization 1967. Current problems in leptospirosis research. Report of a WHO expert group, Geneva. Technical Report Series, p. 32.

Zar J.H. 1996. Biostatical Analysis. 3rd ed. Prentice-Hall, Upper Saddle River, p. 718 . 